\title{
Stent Device
}

National Cancer Institute

\section{Source}

National Cancer Institute. Stent Device. NCI Thesaurus. Code C50190.

A device designed to support a tubular structure, especially the small stainless steel expandable mesh tube inserted within an artery. 